\title{
Serum cholesterol and serum triglycerides in mental retardation
}

\author{
T. LAWLOR* \\ M.B., B.S.(Lond.), M.R.C.(Psych.), D.P.M. \\ F. O'HARA $\dagger$ \\ Ph.D. \\ D. T. BirTWistLE $\dagger$ \\ Ph.D. \\ * Normansfield Hospital, Teddington, Middlesex and $\uparrow$ Polytechnic of North London
}

\begin{abstract}
Summary
Two hundred and thirty-four mentally retarded adult patients, 116 female and 118 male, whose ages ranged from 16 to 81 years had their fasting cholesterol and triglyceride concentrations determined whilst their blood was being taken for routine investigations during a seven week period. These values were compared with those of a healthy adult population who were being screened for these values at the same laboratory. The values of both cholesterol and triglyceride concentrations were found to be significantly lower in the hospital population. A survey of the diet of the hospital patients failed to account for these low values. No significant difference was found between epileptics and non-epileptics, mongols and non-mongols.
\end{abstract}

\section{Introduction}

The difficulties of studying cholesterol and triglyceride levels in a given population in relation to diet, occupation or stress are minimized in patients in a long stay hospital. Thus it is possible to study a given number of patients receiving the same diet in a relatively sheltered environment.

Having noticed during routine investigations that a number of cholesterol levels were low it was decided to examine the cholesterol and triglyceride levels of the hospital population and compare them with those of mentally normal patients being screened at the same laboratory.

This paper presents the results of this comparison and discusses its relationship to the patient's diet.

\section{Materials and method}

Serum cholesterol was determined by the method of Annan and Isherwood (1969), a modification of the Lieberman Burchard reaction, on 234 patients between the ages of 16 and 81 years, the blood for these investigations being taken after the patients had had a $12 \mathrm{hr}$ overnight fast. These values were compared with those of a healthy adult population who were being screened for these values at the same laboratory after a similar $12 \mathrm{hr}$ overnight fast. The hospital population comprised 116 females and $11 \%$ males. Serum triglycerides were determined by the method of Van Handel and Zilversmit (1957). Lipoprotein electrophoresis was carried out on alt patients with raised serum cholesterol and trib glyceride levels in order to eliminate hereditary hyperlipoproteinaemias.

Patients with known endocrine, hereditary biow chemical disorders and diabetes were excludec Patients on anticonvulsants had megaloblastiet anaemias excluded to eliminate the possibilityơ malabsorption states.

Seven day dietary survey

The patients for this survey were picked at randomi A complete record of each patient's intake was made over a 7 day period. Food items were weighe wherever possible and plate wastage was taken into consideration. Careful records of all extra sweets, snacks etc. were made. No changes were made to the normal diet during the period of the survey. The weighing of food was done unobtrusively and it unlikely that any of the patients would be aware of: anything unusual taking place.

\section{Details}

Twenty-two patients-10\% total patients in trialo twelve males; ten females.

\section{Statistical method}

Comparison was made by two-sample $t$-tests, i.e.

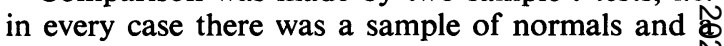
sample of subnormals for each age sex-band. AW overall $t$-test was carried out on the whole of the adult population. Values from non-mongols and mongols, epileptics and non-epileptics, males an females were compared by $t$-tests. Children were excluded from the calculations because of a lack of normal control sample. The calculations were carrie 8 out on an ICL 1905E computer at the Polytechnic oo North London. 


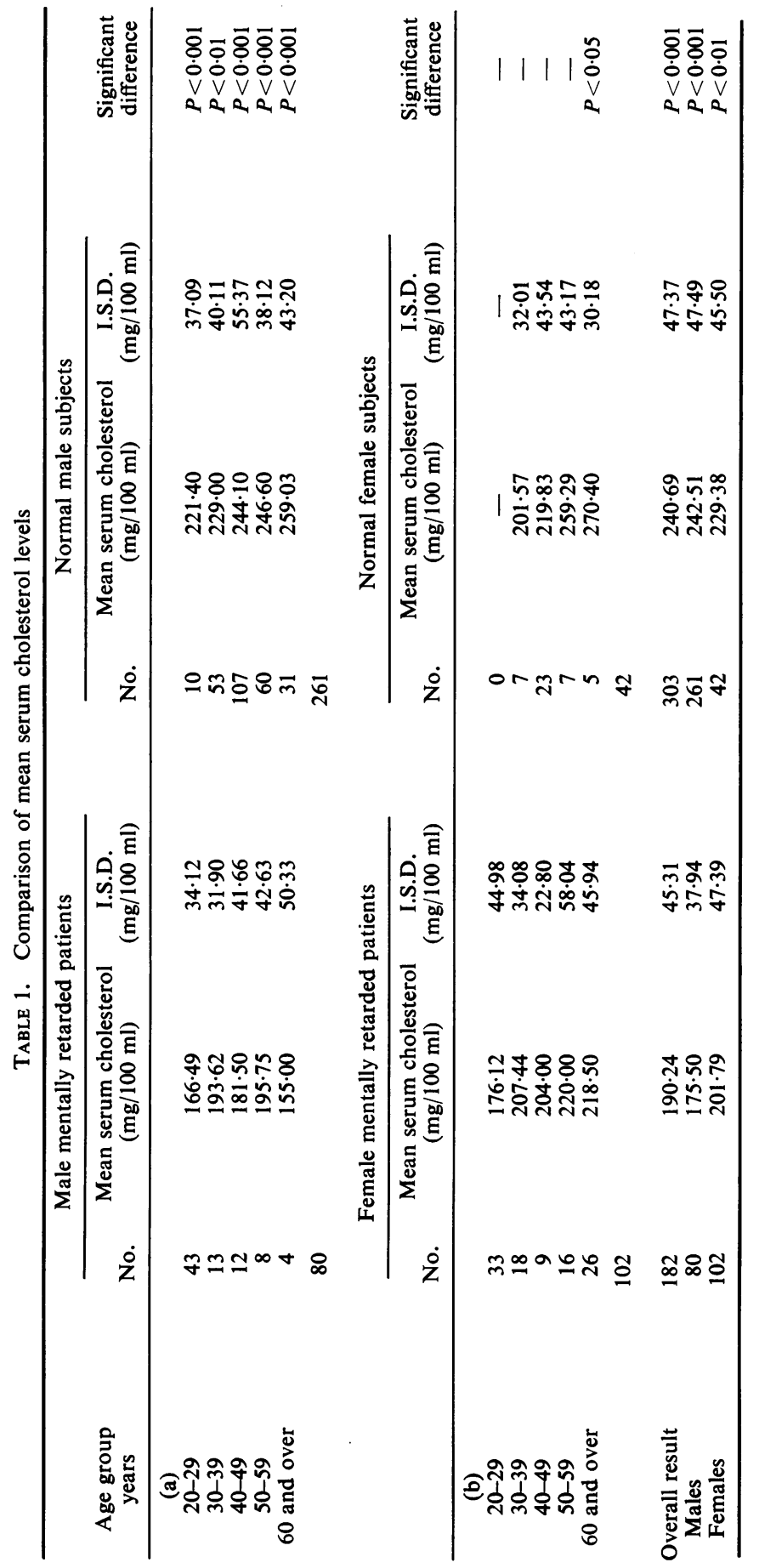




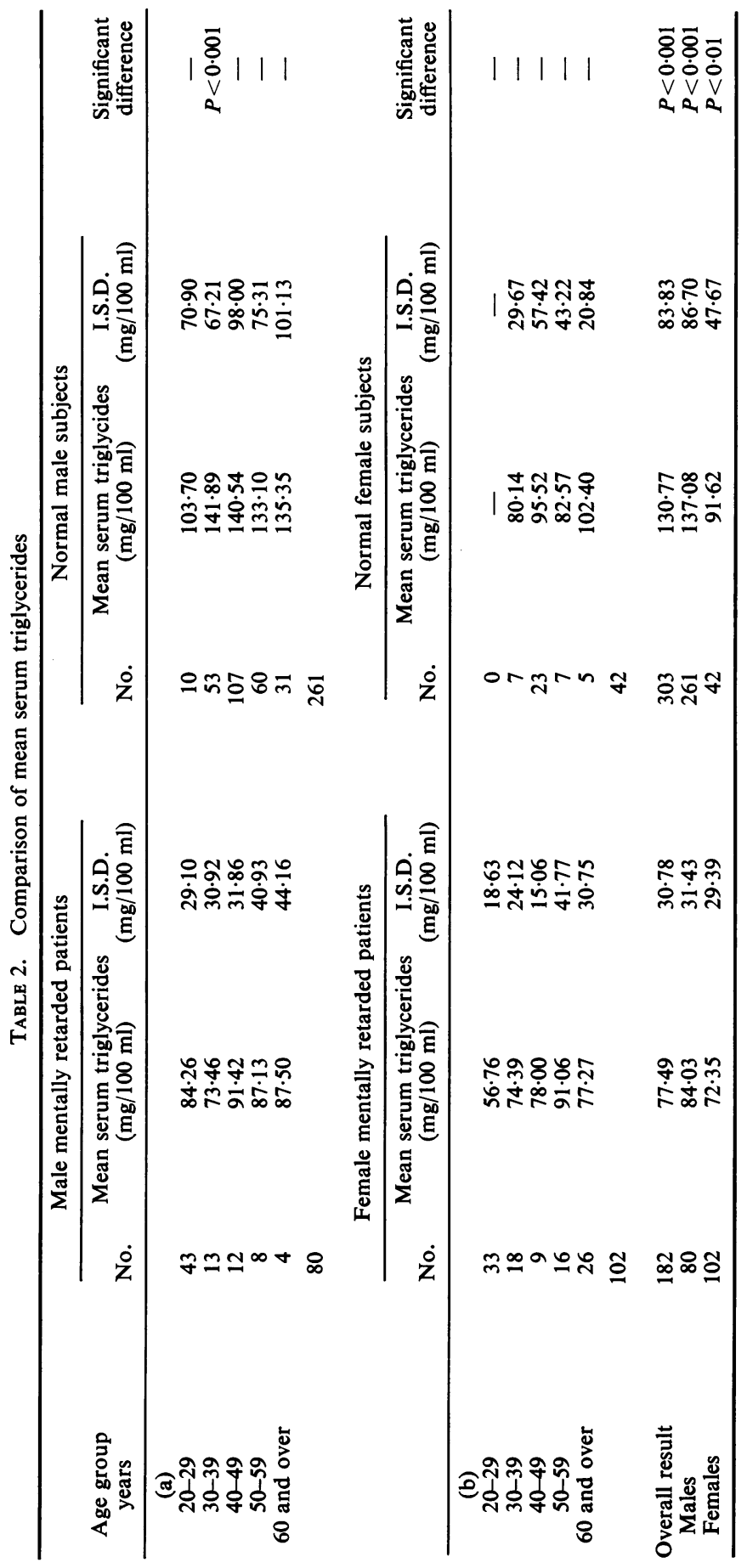




\section{Results}

The overall mean values of both serum cholesterol and serum triglyceride concentrations were found to be significantly lower in both males and females of the hospital population as compared with those of the population screened at the Cavendish Medical Centre. This was not so for all the mean values of age bands (Tables 1a, b, and 2a, b). The discrepancy was presumably due to the small numbers of normal females in some age bands. However, this does not invalidate the overall statistical conclusions.

Comparison of mongols and non-mongols showed no significant difference. This was also the case with epileptics.

\section{Male and female values compared}

Among the mentally retarded patients, a high proportion of males had low cholesterol values, and a high proportion of females had high cholesterol values. The result was statistically very significant (Table 1a, b). This could be accounted for by the number of females who were past the age of the menopause. Three type IV hyperlipoproteinaemias were the only lipoprotein abnormalities found among this mentally retarded population. Among the normal patients no significant difference between males and females appeared. It is, however, worth noting that the number of females in this sample was only one seventh of the total sample.

As might have been expected in both control and mentally retarded groups the males had significantly higher levels of serum triglycerides than the females (Table 2a, b).

The major proportion of dietary fat was from animal sources:

(1) butter was used on bread;

(2) whole milk was used for beverages;

(3) dried whole milk was used for puddings;

(4) lard or dripping was used for frying;

(5) total daily milk intake $\frac{3}{4}-1$ pint per patient;

(6) approximate intake of 5 eggs weekly per patient.

The Department of Health and Social Security (1969) recommended the following nutrient intakes for the United Kingdom:

men 18-35 years sedentary, 2700 calories;

men 36-65 years sedentary, 2600 calories;

Survey-average intake, 2799 calories.

women 18-55 years (most occupations) 2200 calories;

women 56-75 years sedentary, 2050 calories;

Survey-average intake, 2160 calories.

Percentage contribution of protein, fat and carbohydrate to the calories intake normal British diet:

$\begin{array}{lccc} & \begin{array}{c}\text { Survey } \\ \text { Males }\end{array} & \begin{array}{c}\text { Survey } \\ \text { Females }\end{array} \\ \text { Protein } & 10-15 \% & 10 \cdot 7 \% & 12 \cdot 7 \% \\ \text { Fat } & 35-40 \% & 38.7 \% & 39 \cdot 7 \% \\ \text { Carbohydrate } 45-50 \% & 50 \cdot 6 \% & 47 \cdot 6 \%\end{array}$

The results show that the calorie intake was within the recommended range.

TABLE 3. Average daily intake over a period of seven daysmentally retarded patients

\begin{tabular}{lcccr}
\hline Males & $\begin{array}{c}\text { Protein } \\
\text { (grams) }\end{array}$ & $\begin{array}{c}\text { Fat } \\
\text { (grams) }\end{array}$ & $\begin{array}{c}\text { Carbo- } \\
\text { hydrate } \\
\text { (grams) }\end{array}$ & Calories \\
\hline 1 & $85 \cdot 0$ & $131 \cdot 9$ & $390 \cdot 6$ & 3065 \\
2 & $79 \cdot 5$ & $138 \cdot 5$ & $394 \cdot 5$ & 3114 \\
3 & $71 \cdot 3$ & $109 \cdot 8$ & $329 \cdot 7$ & 2567 \\
4 & $78 \cdot 3$ & $124 \cdot 9$ & $377 \cdot 5$ & 2916 \\
5 & $77 \cdot 2$ & $130 \cdot 9$ & $365 \cdot 5$ & 2928 \\
6 & $77 \cdot 4$ & $118 \cdot 9$ & $360 \cdot 1$ & 2804 \\
7 & $72 \cdot 8$ & $128 \cdot 8$ & $381 \cdot 1$ & 2948 \\
8 & $74 \cdot 0$ & $113 \cdot 7$ & $342 \cdot 2$ & 2664 \\
9 & $68 \cdot 6$ & $121 \cdot 9$ & $341 \cdot 6$ & 2682 \\
10 & $71 \cdot 6$ & $104 \cdot 1$ & $314 \cdot 6$ & 2458 \\
11 & $75 \cdot 7$ & $116 \cdot 5$ & $356 \cdot 2$ & 2743 \\
12 & $75 \cdot 7$ & $115 \cdot 9$ & $343 \cdot 1$ & 2697 \\
Mean & $75 \cdot 6$ & $121 \cdot 3$ & $358 \cdot 0$ & 2799 \\
s.d. & $4 \cdot 38$ & $10 \cdot 05$ & $24 \cdot 87$ & 200 \\
$\%$ of calorie intake & $10 \cdot 7 \%$ & $38 \cdot 7 \%$ & $50 \cdot 6 \%$ & \\
& & & & \\
Females & & & & \\
1 & $65 \cdot 7$ & $92 \cdot 4$ & $266 \cdot 2$ & 2145 \\
2 & $64 \cdot 1$ & $85 \cdot 5$ & $231 \cdot 9$ & 1953 \\
3 & $67 \cdot 2$ & $89 \cdot 3$ & $240 \cdot 4$ & 2014 \\
4 & $73 \cdot 8$ & $100 \cdot 6$ & $281 \cdot 9$ & 2313 \\
5 & $72 \cdot 6$ & $106 \cdot 2$ & $284 \cdot 4$ & 2373 \\
6 & $69 \cdot 1$ & $100 \cdot 4$ & $279 \cdot 0$ & 2274 \\
7 & $76 \cdot 0$ & $103 \cdot 9$ & $267 \cdot 7$ & 2299 \\
8 & $66 \cdot 7$ & $89 \cdot 5$ & $224 \cdot 1$ & 1969 \\
9 & $65 \cdot 0$ & $93 \cdot 2$ & $252 \cdot 7$ & 2099 \\
10 & $68 \cdot 6$ & $97 \cdot 4$ & $253 \cdot 7$ & 2158 \\
Mean & $68 \cdot 9$ & $95 \cdot 8$ & $258 \cdot 2$ & 2160 \\
s.d. & $4 \cdot 01$ & $6 \cdot 89$ & $21 \cdot 23$ & 144 \\
$\%$ of calorie intake & $12 \cdot 7 \%$ & $39 \cdot 7 \%$ & $47 \cdot 6 \%$ & \\
\hline & & & & \\
\hline & & & & \\
& & & &
\end{tabular}

\section{Discussion}

Eastham and Jancar (1969) published their results on serum cholesterol estimations taken at random from 1400 mentally retarded patients and they statistically examined the relationship between their results and those of a large survey carried out in the United States by Moor and Gordon (1967). Eastham and Jancar (1969) found their results were significantly lower. The population of normals screened by the Cavendish Medical Centre ranged in age groups from 20 to 60 years plus and consisted of men and women from all walks of life and varied occupations. As an economic grouping, they all had the same means to avail themselves of a private medical check up, including an estimation of their fasting serum cholesterol and triglyceride levels in addition to electrophoresis for the detection of abnormal 
lipoprotein patterns for the diagnosis of hyperlipoproteinaemias. Whilst it may be objected that the economic category of the control patients might cast doubt on their acting as a normal control population sample, it was felt that the lack of any large scale survey of normal cholesterol and triglyceride values in this country, in addition to the difficulties inherent in comparing results of different laboratories on patients in different countries far outweighed this consideration.

It is of interest to note that the overall means both of cholesterol and triglyceride levels of the mentally retarded patients, were significantly lower than those obtained by Boyne et al. (1969) and that of the serum cholesterol obtained by McDonald, Lidwell and Wright (1965). The latter authors studied 976 air force recruits while the former studied a representative sample of a pharmaceutical company's employees numbering 200 .

A statistical comparison by Richards and Sylvester (1969) was carried out into the causes of death in a population of mentally retarded patients with those of the general population. Arteriosclerosis, as a cause of death at post mortem was found to be less in the former group.

A cause for the low serum lipid levels in the mentally retarded patients that obviously suggests itself is the constituents of the patients' diet. The dietary survey carried out on a sample of patients showed that the calorie intake was well within the levels laid down by the Department of Health (1969) and that the fat intake was in no way deficient quantitatively or qualitatively in animal fat, these patients having their food cooked in the latter and having liberal amounts of butter on their bread.

In animal studies, Mills, Chapman and McTaggart (1972) have shown that increases in animal fat in the diet can result in a decrease in serum triglyceride levels. However, the amount of fat administered in this group of patients was not sufficiently in excess to account for the low levels obtained.

There was no evidence of a low sucrose level in the diet and in view of the availability of the hospital shop to patients, where confectionery may be obtained, the lack of sugar as a cause of low triglyceride levels can be discounted.

Having failed to account for these findings on the basis of diet, the possibility of a sheltered environ- ment with absence of stress as a causative factor comes to mind.

One other possibility is that these patients may have different serum lipoprotein patterns compared with other more normal populations.

Recent work by Mills, Chong and Tayleur (1972) employing a serial ultracentrifugal technique has shown a variation in serum lipoprotein compositions in differing populations and social classes and this could be the basis of a future study.

\section{Acknowledgments}

We would like to thank Mr R. L. Bassett of the Cavendish Medical Centre for carrying out the investigations, Mrs M. Irish, Dietitian, Staines Group Hospital Management Committee, for undertaking the dietary survey, and the Nursing Staff of Normansfield Hospital for their co-operation in this study.

We are also grateful to Professor I. McDonald, Professor of Physiology, Guys Hospital, for his advice with this study and for his helpful suggestions in preparing the manuscript.

This project was made possible by a research grant from the North West Metropolitan Regional Hospital Board.

\section{References}

AnNAN, W. \& IsHerwood, D.M. (1969) An automated method of direct determination of total serum cholesterol. Journal of Medical Laboratory Technology, 26, 202.

Boyne, D.R., Crossley, J.N., Abrams, M.E., Jarrett, R.te \& KeENS, H. (1969) Oral glucose tolerance and relatee factors in a normal population sample. British Medic Journal, 1, 595.

DePartment OF Health (1969) Recommended intakes of Nutrients for the United Kingdom. Reports on Public Health and Medical Subjects (No. 120) H.M.S.O.

EASTHAM, R.D. \& JANCAR, J. (1969) Serum cholesterol in mental retardation. British Journal of Psychiatry, 115, 1013.

McDonald, J., Lidwell, O.M. \& WRight, E.A. (1965) Serum cholesterol, smoking and body build. British Journal Preventative Social Medicine, 19, 111.

Mills, G.L., Chapman, M.J. \& McTaggart, F. (1972) Effects of diets on guinea-pig serum lipoproteins. Biochimica et Biophysica Acta, 260, 401.

Mills, G.L., ChONG, Y.H. \& TAYleUR, C.E. (1972) Variations in composition of serum low density lipoproteins in healthy men. Clinica, Chemica Acta, 42, 273.

MOORE, F.E. \& Gordon, T. (1967) Serum cholesterol levels of adults. National Centre for Health Statistics, Series 11, No. 22.

Richards, B.W. \& Sylvester, P.E. (1969) Mortality trends in mental deficiency institutes. Journal of Mental Deficiency Research, 13, Part 4.

Van Handel, E. \& Zilversmit, D.B. (1957) Micro method for the direct determination of serum triglycerides. Journal of Laboratory and Clinical Medicine, 50, 152. 